Landslides (2021) 18:513-520

DOI 10.1007/s10346-020-01588-z

Published online: 19 January 2021

(c) Springer-Verlag GmbH Germany

part of Springer Nature 2021

\section{Kazuo Konagai \\ More than just technology for landslide disaster mitigation: signatories to The Kyoto Landslide Commitment 2020-No. 1}

The Kyoto Landslide Commitment 2020 (KLC 2020, Sassa 2019) provides a shared blueprint for implementing landslide disaster mitigation frameworks further beyond the "Sendai Landslide Partnerships 2015-2025 for Global Promotion of Understanding and Reducing Landslide Disaster Risk." The KLC 2020 has officially been launched since the online launching session of KLC 2020, 5 November 2020 (Sassa 2020, 2021). Our actions aiming at the behavioral objectives blueprinted in the KLC 2020 will be reviewed for its further development, on the Fifth World Landslide Forum, which has been postponed in the wake of the coronavirus pandemic to 2 to 6 November 2021. There are currently total 90 signatories to the KLC 2020 and it is thus very timely to start a new serial to introduce monthly the signatories to the KLC in the journal Landslides. The first installment in this introductory series comprises total 14 signatories, namely, 6 governmental and/or international organizations, 4 ICL supporting organizations (and simultaneously ICL full members), and 4 ICL full members. They follow hereafter.

\section{Governmental and/or international organizations}

Integrated Research on Disaster Risk (IRDR)
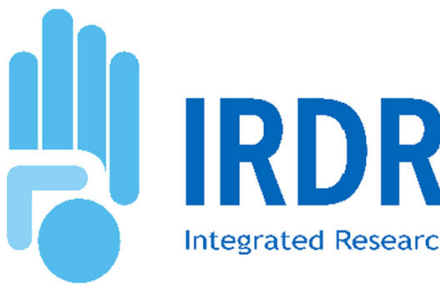

Integrated Research on Disaster Risk

Date of signature: 18 September 2019

URL: http://www.irdrinternational.org/

Started in 2010, Integrated Research on Disaster Risk (IRDR) is a decade-long research program co-sponsored by the International Science Council (ISC) and the United Nations Office for Disaster Risk Reduction (UNDRR). IRDR promotes a multidisciplinary approach to dealing with the challenges brought by natural disasters, mitigating their impacts, and improving related policy-making mechanisms (www.irdrinternational.org). The complexity of the task is such that it requires the full integration of research expertise from the natural, socioeconomic, health, and engineering sciences as well as policymaking, coupled with an understanding of the role of communications and public and political responses to reduce the risk.
The overall mission of IRDR is to develop transdisciplinary, multi-sectorial alliances for the following:

1. In-depth, practical disaster risk reduction research studies

2. The implementation of effective evidence-based disaster risk policies and practices $>$

Its main research objectives are the following:

- Characterization of hazard, vulnerability, and risk

- Effective decision-making in complex and changing risk context

- Reducing risk and curbing losses through knowledge-based actions

It is through this mission IRDR contributes to Sendai Framework for Disaster Risk Reduction 2015-2030 and to the 2030 Agenda for Sustainable Development.

At the 4th World Landslide Forum held in Ljubljana, Slovenia, in 2017, the Chair of IRDR Scientific Committee signed ISDR-ICL Sendai Partnership 2015-2025 for Global Promotion of Understanding and Reducing Landslide Disaster Risk. This marked the official commitment of IRDR toward cooperation with ICL and its main partners. Since 2017, IRDR has taken actions through its own program in the development of Disaster Risk Reduction (DRR hereafter) research and technical training on landslides and mountain hazards. The actions include: (1) UNESCO-IRDR cooperation in the 3 rd Huangshan Dialogue on UNESCO Sites and Sustainable Development 2018 where a specific session on Disaster Risk Assessment and Mitigation for UNESCO Sites (IDAs) addressed the issues of landslides disaster risks at IDAs; (2) The special session on DRR in IDAs in May 2019 at the International Conference on Silk-roads Disaster Risk Reduction and Sustainable Development, which brought further the international discussion; and (3) Two IRDR working papers to address landslide risk in Himalaya mountain areas and landslides in permafrost zones in Northern Asia. IRDR and its International Programme Office (IPO) also actively participated in scientific symposium of ICL/IPL and the preparation work of WLF5.

In this context, IRDR anticipates very active roles in its new progamme phase for the implementation of KLC 2020. These are especially in Action 1 for people centered early warning, Action 2 on hazard and vulnerability mapping and Action 5 in promotion of open communication with local governments, communities and society at large through integrated research, capacity building, knowledge transfer and education, and Action 6 to investigate the effect of climate change on landslide risk. 
Sabo Planning Division, Ministry of Land Infrastructure, Transport and Tourism, Japan

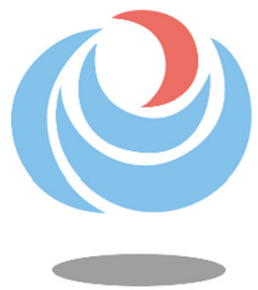

Ministry of Land, Infrastructure, Transport and Tourism

Date of signature: 18 September 2019

URL: https://www.mlit.go.jp/en/index.html

In 2018, the Sabo Planning Division, Ministry of Land Infrastructure, Transport and Tourism (MLIT hereafter) marked 80 years since its predecessor organization; the Sabo Department of MLIT was established in 1938. The Sabo Department has been mandated to take necessary countermeasures for sediment disasters in Japan. Specifically, it has been responsible for measures against sediment runoff from upstream areas of rivers, such as debris flows, landslides, etc. The Sabo Department has long been supporting the activities of $\mathrm{WLF}_{5}$ and has endorsed the KCL 2020 and signed it in September 2019. It also serves as an advisor to the journal Landslides. It supported every relevant international event such as the 2018 INTERPRAEVENT Congress held in Japan (http://www.interpraevent.at/ ?tpl=news.php\&kategorie $=1 \& i d=112)$. It has also been contribut ing to the activities of the National Institute for Land and Infrastructure Management (NILIM), the research division of MLIT, and the Public Works Research Institute (PWRI), one of Japanese National Research and Development Agencies, by making a number of research presentations.

In addition to its research activities, it has also made numerous contributions to sediment disaster countermeasures, including those for landslides. In collaboration with the Japan International Cooperation Agency (JICA), MLIT sent engineers to many landslide prone areas in countries such as Indonesia, Nepal, the Philippines, etc., to help develop sediment disaster countermeasure technologies. In recent years, it has promoted cooperation on countermeasures against sediment disasters in Brazil and Sri Lanka by providing technical support to develop hazard maps and early warning information systems. Given the worldwide climate change leading to a higher frequency of landslide activity, the Sabo Planning Division, MLIT, anticipates its role to expand providing further technical supports to developing countries in line with the KLC 2020 .
National Civil Protection Department, Italian Presidency of the Council of Ministers

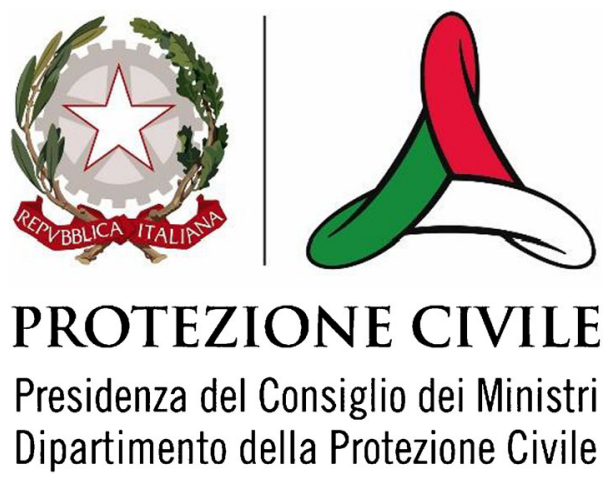

Date of signature: 18 September 2019

URL: http://www.protezionecivile.gov.it/home

The Italian Civil Protection Department, an office of the Presidency of the Council of Ministers, in close and synergic cooperation with regional and local governments, coordinates a variety of actions and activities aimed at preventing, forecasting, and monitoring a number of natural and technological hazards and risks. Landslides are one of the primary hazards considered by the Civil Protection Department. The specific interest of the Civil Protection Department on landslides and their problems is due to the extremely large density of landslides in Italy, and the severe vulnerability to landslides of the population, the built-up environment, the infrastructure, and the environment. Since its inception, the Italian Civil Protection Department has had a close collaboration with the academic and research world and chiefly with research scientists interested in advancing knowledge about landslides, their hazards, and risk, in Italy and elsewhere in the world. For more than three decades, the Department has funded, through its centers of expertise, three of which are members of the International Consortium of Landslides (ICL), research and technological development activities and the dissemination of a risk culture, on several landslide-related topics, including the mapping and monitoring of landslides, also using innovative remote sensing technologies from the ground, air, and satellites, early warning systems, from the local to the national scales, and landslide risk assessment, with emphasis on the risk to the population of Italy. A signatory of the Sendai, 2015-2025 agreement, the Civil Protection Department has a keen interest on the KLC 2020 agreement aimed at reducing the risk of landslides, in Italy and elsewhere.

\section{Global Risk Forum GRF Davos, Davos, Switzerland}

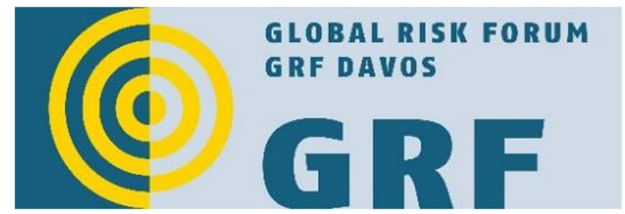

Date of signature: 18 September 2019

URL: https://grforum.org/about-us/team/ 
The Foundation Global Risk Forum GRF Davos is an international organization, founded in 2008 and based in Davos, Switzerland, and aims, through its various activities, at bridging the various gaps between science, administration, the private sector, the practice, and the public regarding risk reduction, disaster management and resilience, climate change mitigation, and adaptation. "From Thoughts to Action" by closely linking practice, science, policy, and decisionmaking in the search for sustainable solutions-this is the credo of GRF Davos, thus promoting a truly integrative and participative approach to ensure that the valuable lessons learned about risk reduction and disaster management from a wide spectrum are applied correctly to create safer, more resilient, and thus sustainable societies for the benefit of communities, countries, and regions. GRF Davos is based on three pillars-conferences, education, and research and development. The conference pillar already started with the 1st International Disaster and Risk Conference IDRC in Davos, Switzerland, in 2006. It is organized as a biennial global conference in Davos since 2006, with some regional conferences in China since 2007, and since 2017 also in Sendai, Japan, with GRF as partner of the Sendai World Bosai Forum. GRF also provides education and training courses at universities and does some research, development, and consulting activities in its third pillar. GRF Davos through its various activities aims at serving as a Centre of Excellence in knowledge and know-how exchange for the application of timely and appropriate risk management strategies, tools, and practical solutions, thus reducing vulnerability for all types of risks and disasters and increase resilience to protect life, property, environment, critical infrastructures, and all means of businesses on a sustainable basis. GRF Davos strives for an improved understanding, analysis, assessment, and management of risks and disasters that affect human safety and security at large. COVID-19 in particular demonstrates how people are highly vulnerable at a global scale and that most countries were not prepared to cope with a pandemic disease due to the lack of an integrative risk management approach at national levels. Prevention and resilience measures are important for people and communities to render social groups more adaptable to such kind of disaster. GRF Davos since its beginning follows a multisectors and disciplines approach in order to holistically address risks and manage disasters at all levels. That is why GRF Davos strongly supports all the valuable initiatives, programs, and actions of ICL, in particular the KLC 2020 Actions. GRF Davos was also among the first group of partners to sign on the planned Kyoto 2020 commitment for global promotion of understanding and reducing landslide disaster risk.

International Association for Engineering Geology and the Environment

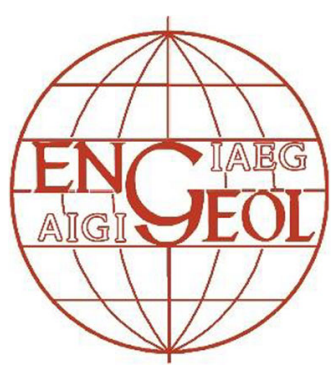

Date of signature: 1 October 2019

URL: https://www.iaeg.info/

"Engineering Geology is the science devoted to the investigation, study and solution of the engineering and environmental problems which may arise as the result of the interaction between geology and the works and anthropological activities as well as to the prediction and of the development of measures for prevention or remediation of geological hazards" (IAEG Statutes, 1992).

The International Association for Engineering Geology and the Environment (IAEG) was founded in 1964 and is affiliated to the International Union of Geological Sciences (IUGS). IAEG is a worldwide scientific society with more than 4500 members and 66 national and regional groups. There are also 19 active professional commissions and groups in different fields. IAEG publishes an official academic journal by Springer-Verlag the Bulletin of Engineering Geology and the Environment with 4 issues a year. And IAEG awards the Hans Cloos Medal for the outstanding engineering geologist, Richard Wolters Prize for young professional and Marcel Arnould Medal for IAEG member who has made a significant contribution to the engineering geology profession in their region and given outstanding service to the Association every 2 years. The official languages of IAEG are English and French.

The aims of IAEG are to promote and encourage the advancement of Engineering Geology through technological activities and research, to improve teaching and training in Engineering Geology, and to collect, evaluate, and disseminate the results of engineering geological activities on a worldwide basis.

\section{International Geosynthetics Society (IGS)}

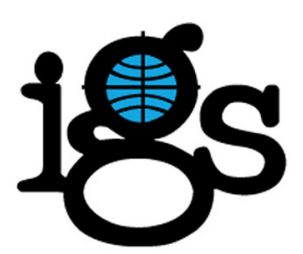

\section{International Geosynthetics Society}

Date of Signature: 18 September 2019

URL: https://www.geosyntheticssociety.org/

The International Geosynthetics Society (IGS) is a learned society dedicated to the scientific and engineering development of geotextiles, geomembranes, related products, and associated technologies. The vision of the IGS is that geosynthetics can be recognized to be fundamental to sustainable development by providing technological and engineering solutions to answer societal and environmental challenges.

The International Geosynthetics Society can trace its roots back to 1977 when the International Conference on the use of Fabrics in Geotechnics occurred in Paris, France. Today, the event is referred to as the First International Conference on Geotextiles. Founded in Paris, France, in 1983 as the International Geotextile Society (IGS), the IGS General Assembly approved the change of name to the International Geosynthetics Society in 1994. Since the society's beginnings, the IGS has grown to over 4000 members including corporate, individual, and student members. With 47 chapters worldwide, it is easy to be involved with the society by joining a local IGS chapter. 
Geosynthetics are now being recognized as fundamental to sustainable development as they can reduce carbon footprint by minimizing the use of natural resources. The IGS has recently launched "Committee on Sustainability" to increase awareness on sustainable development in relation to circular economy in the society. The committee is expected to pave the way forward for the role and contribution of geosynthetics on sustainable development as well. Geosynthetics products for slope reinforcement, drainage, and erosion control, such as geogrids, geotextiles, and geocomposites, among others, are being extensively used in man-made and natural slopes as mitigation measures for slope failure. As the related technology evolves, geosynthetics products will further help reduce landslide-related disasters.

Italian Chapter of IGS successfully organized a workshop on the use of geosynthetics at World Landslide Forum (WLF) took place in Slovenia in 2017. Later IGS also participated 2019 ICL-IPL Conference which was held at UNESCO Headquarters, Paris, on 16-19 September 2019 and signed KLC 2020 as the first signatory. International Geosynthetics Society will continuously contribute to the 2030 Agenda for Sustainable Development, as well as to the Sendai Framework for Disaster Risk Reduction 2015-2030.

ICL supporting organizations as well as ICL full members

\section{Geotechnical Engineering Office, Civil Engineering and Development} Department, Hong Kong SAR, China1

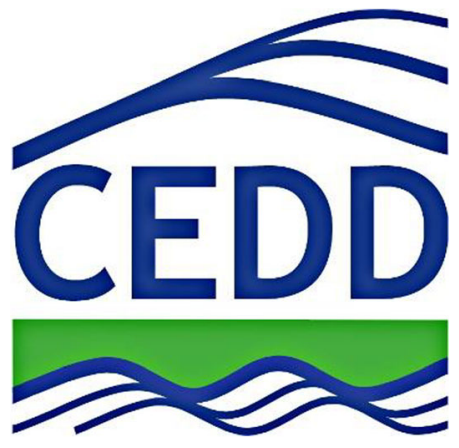

Date of signature: 18 September 2019

URL: https://www.cedd.gov.hk/eng/our-major-services/geotechnical/index.html

With sustained and dedicated efforts, the slope safety system developed by the Geotechnical Engineering Office (GEO) has been managing effectively the landslide risk of Hong Kong. The GEO will continue its effort in improving the slope safety system through a range of new initiatives pertinent to making advancements in landslip warning, formulating new strategies for strengthening community resilience, and undertaking cuttingedge technical development work for enhancing landslide risk management practice. The work is of direct relevance to a number of priority actions of KLC 2020 as detailed below.

(a) Advancement in landslip warning (pertinent to Priority Actions 1 and 3)

The GEO operates the Landslip Warning (LW) System in Hong Kong, based on the number of landslides estimated from correlations between rainfall intensity and landslide frequency. While this LW is established to target at raising the landslide risk awareness of the general public during heavy rainfall, the GEO develops a smart landslide detection system with an aim to provide alerts to the communities at locations vulnerable to landslides. The system, comprising IoT sensors to detect landslide impact, is installed in protective barriers. Any landslide impact on the barriers will immediately trigger alerts disseminated through a LoRA-based radio gateway to the GEO and the local community at the downstream of the barriers for emergency responses.

b) Strengthening community resilience (pertinent to Priority Action 5)

The GEO has been conducting a wide range of public education campaigns on slope safety to build up community resilience against landslide hazard. In order to support the formulation of the new strategy for further enhancing the community resilience, the GEO has engaged social scientists to gauge the public perception on landslide risk, identify target groups that most require engagement, and devise effective slope safety messages. Novel technology has been adopted in the public education campaigns. Virtual reality (VR) and augmented reality (AR) games and videos conveying the slope safety messages and self-help tips in case of landslide emergency are developed. VR training packages pertinent to handling landslide emergency have also been launched.

c) Cutting-edge technical development work (pertinent to Priority Action 9)

The GEO has commissioned a range of collaborative projects with different research agencies covering enhancement of landslide hazard identification and design of landslide risk mitigation measures. One of the examples is the application of machine learning to carry out automatic landslide mapping on aerial photographs for natural terrain hazard assessment.

We commit ourselves to share our experience of landslide risk management and research results with the world's slope safety practitioners through technical exchange activities and publications in journal Landslides and will proactively participate in suitable collaboration projects with endeavors to achieve the goals of KCL 2020.

UNESCO Chair for the prevention and sustainable management of geohydrological hazards, University of Firenze (UNIFI)

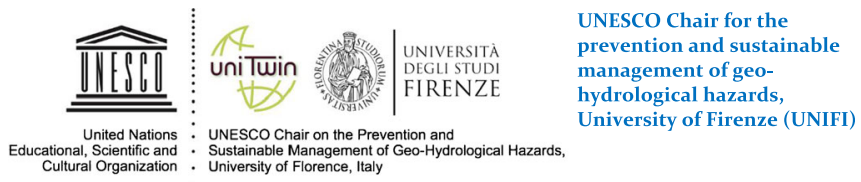

Date of signature: 18 September 2019

URL: http://www.unesco-geohazards.unifi.it

Facebook: https://www.facebook.com/unesco.geohazards. florence

The UNESCO Chair for the prevention and sustainable management of geo-hydrological hazards was established at the University of Firenze (UNIFI) and it is focused on applied research 
and higher education in the field of geohazards threatening human life, property, cultural heritage, and the natural and built environment.

The Chair actively promotes and develops (i) innovative technologies for the prevention and mitigation of geo-hydrological hazards; (ii) tools and procedures for supporting risk reduction policies and the management of emergencies for the safety of human life; (iii) the protection of cultural heritage threatened by geo-hydrological hazards; and (iv) research at the international level by offering scientific facilities to postgraduate students and visiting researchers.

The University of Firenze signed the ISDR-ICL Sendai Partnership 2015-2025 for the global promotion of understanding and reducing landslide disaster risk, which was also signed by UNESCO and the Italian Government, among other partners, and UN organizations. The Chair actively contributes to the Sustainable Development Goals of the UN 2030 Agenda for Sustainable Development and signed the Geneva Milestone in 2017 as a member of the UNESCO network of Chairs in Natural Sciences.

The Chair, formerly as Department of Earth Sciences, University of Firenze, has long been a member of ICL since its foundation in 2002 and has been awarded four times (2008-2011, 2011-2014, 2014-2017, 2017-2020) the title of the World Centre of Excellence

Geoenvironmental Hazard Research Center, Korea Institute of Geoscience and Mineral Resources

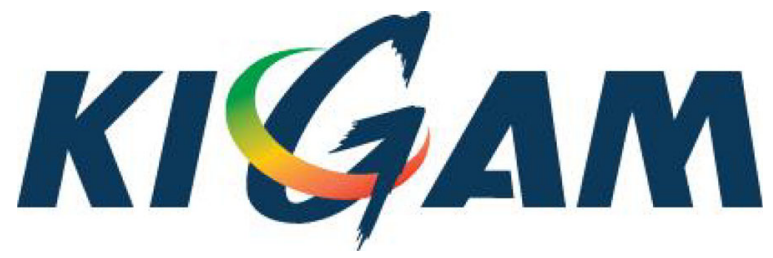

(WCoE) in landslide risk reduction by the Global Promotion Committee of International Programme on Landslides of UNISDR. Since 2002, the UNESCO Chair has coordinated or has been involved in several ICL/IPL projects and UNESCO Chair is the proposer of the ICL Italian network that has been officially established in December 2018. The Chair has contributed to the growth and success of Landslides: Journal of the International Consortium on Landslides and it will host the 6th World Landslide Forum in Firenze, in 2023.

The Chair is involved in activities of international cooperation for the prevention and reduction of geo-hydrological risk in the UNESCO World Heritage sites, particularly in less developed countries.

The Chair has also been the center of competence on geohydrological risk for the Italian Civil Protection Department, since 2005; a member of the International Consortium on Geo-disaster Reduction (ICGdR), since 2014; a member of the Global Alliance of Disaster Research Institutes (GADRI), one of founding members since 2015; and a member of the Joint International Centre on Natural Hazards (JIC-Nh), a co-founding member since 2016.

In 2019, the UNESCO Chair has signed KLC 2020 and will strongly support its actions, especially KCL 2020 Actions 1, 2, 3, 6 , and 9 .

\section{Geo-Environmental Hazard Research Center, Korea Institute of Geoscience and Mineral Resources}

Date of signature: 20 August 2019

URL: www.kigam.re.kr

The landslide hazard research team of Korea Institute of Geoscience and Mineral Resources (KIGAM) is conducting research on the development of landslide prediction models, monitoring, and early warning systems, starting with a study on the characteristics of landslide occurrences in the Republic of Korea. Recently, a physically based landslide prediction model and a robust early warning system equipped with a model capable of predicting landslides 24 hours in advance were developed on the basis of rainfall forecasting technology using weather radar information. K-LAMOS (KIGAM landslide monitoring system) has been built in and operated at 13 monitoring stations in 9 different mountainous areas since 2014. Also, the prototype landslide early warning system at Mt. Jiri area $\left(20 \mathrm{~km}^{2}\right)$ was developed in 2019 and this system has been improved and operated.

The landslide hazard research team of KIGAM joined the International Consortium on Landslides (ICL) with full membership in 2005 and has deeply been committed to the ICL activities. In 2006, KIGAM participated in the joint initiative of the ICL Tokyo Action Plan, and in 2007, KIGAM and ICL signed a memorandum of understanding (MOU). The research theme of the MOU was the
Asian Joint Research Project for Early Warning of Landslide. In 2011, the ICL North-East Asia Network (ICL-NEA) was formed; and the International Symposium on Landslides organized by Korea Forest Research Institute (KFRI) and ICL-NEA was held from 13 to 15 June 2013, in Seoul, Korea.

The landslide hazard research team of KIGAM is conducting international research networking in northeast Asian research organizations including Kyoto University, National Taiwan University, and Shimane University. Since 2009, it has co-hosted the "Korea-Italy Joint Seminar on Landslide Hazards" every other year. Main researchers from Korea Institute of Civil Engineering and Building Technology (KICT), Sejong University in Korea, University of Firenze, Research Institute for Geo-Hydrological Protection (CNR-IRPI), and University of Bologna in Italy participated in every seminar. It also hosted the "Regular Training Course on Landslide Hazards" organized by KIGAM International School for Geoscience Resources (IS-Geo, https:// isgeo.kigam.re.kr/eng/) from 2011 to 2018. The participants were public officials and researchers from developing countries such as South East \& Central Asian Countries and African Countries, including Korea. 
Faculty of Civil and Geodetic Engineering, University of Ljubljana

Univerza $v$ Ljubljani

Fakulteta za gradbeništvo in geodezijo

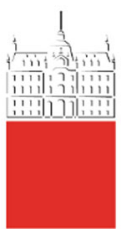

Date of signature: 18 September 2019

URL: https://www.en.fgg.uni-lj.si/

In 2019, Faculty of Civil and Geodetic Engineering of the University of Ljubljana (UL FGG; https://www.en.fgg.uni-lj.si/) celebrated its centennial. UL FGG, covering technical disciplines of civil and geodetic engineering, as well as water science and technology, has been involved in landslide risk reduction activities in Slovenia for decades. For more than 20 years, UL FGG is supporting activities of the International Research Society INTERPRAEVENT (www.interpraevent.at) in the field of natural disaster risk reduction including landslide risk. In the field of capacity building, UL FGG offers courses for graduate and postgraduate students in landslide mechanics, dynamics and stabilization, and landslide risk mitigation.

Since 2008, UL FGG has been a full member of the International Consortium on Landslides (ICL) and is gradually intensifying its contributions to the ICL worldwide efforts for landslide risk reduction and international promotion of landslide research. UL FGG has been awarded four times (2008-2011, 2011-2014, 20142017, 2017-2020) the title of the World Centre of Excellence (WCoE) in landslide risk reduction. UL FGG has contributed to International Programme on Landslides (IPL) by various research projects approved by the IPL Global Promotion Committee; to the growth and success of the Landslides: Journal of the International Consortium on Landslides; to organization of triennial World Landslide Forums (WLF), especially by hosting the 4 th WLF in Ljubljana in 2017; and to the ICL thematic and regional networks by active involvement into the Landslide Monitoring and Warning Thematic Network and the ICL Adriatic-Balkan Regional Network.

In 2016, the UNESCO Chair in water-related disaster risk reduction (www.unesco-floods.eu) was established at University of Ljubljana, hosted by UL FGG, thus contributing to the UNESCO/KU/icl landslide and water-related disaster risk management for Society and the Environment Cooperation Programme, signed in 2010 .

In 2019, UL FGG hosted, together with the Slovenian Chamber of Engineers, the World Construction Forum 2019 in Ljubljana on "Buildings and Infrastructure Resilience." One of the WCF 2019 themes on Disaster Risk Management and Governance for Resilient Communities was co-organized by the World Federation of Engineering Organizations (WFEO) — all lectures given are available at www.wcf2019.org, as a contribution to Open Science efforts.

UL FGG continuously contributes to the 2030 Agenda for Sustainable Development, as well as to the Sendai Framework for Disaster Risk Reduction 2015-2030. Therefore, in 2019, UL FGG has signed KLC 2020 and will strongly support its actions, especially KCL 2020 Actions 2, 5, 6, 9, and 10.

ICL full members

Geological Survey of Canada, NRCan, Canada

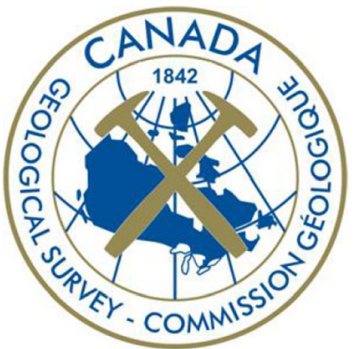

Date of signature: 18 September 2019

URL: https://www.nrcan.gc.ca/science-data/science-research/ earth-sciences/geological-survey-canada/17100

The Geological Survey of Canada (GSC) is part of the Earth Sciences Sector of Natural Resources Canada. The GSC is Canada's oldest scientific agency and one of its first government organizations. It was founded in 1842 to help develop a viable Canadian mineral industry by establishing the general geological base on which the industry could plan detailed investigations. Throughout its long and colorful history, the GSC has played a leading role in exploring the nation. Today, the GSC is Canada's national organization for geoscientific information and research. Its world class expertise focuses on the sustainable development of Canada's mineral, energy, and water resources; stewardship of Canada's environment; management of natural geological and related hazards; and technology innovation. The GSC celebrated its 175th anniversary in 2017 which coincided with Canada's 15oth anniversary of confederation.

Since 2002, the GSC has been a full member of the International Consortium on Landslides (ICL) and has been gradually intensifying its contributions to the ICL worldwide efforts for landslide risk reduction and international promotion of landslide research. The GSC has been twice recognized as a World Centre of Excellence (WCoE) in landslide risk reduction. Throughout its membership, the GSC has contributed actively to the International Programme on Landslides (IPL) through a number of research projects approved by the IPL Global Promotion Committee; to the growth and success of Landslides: Journal of the International Consortium on Landslides, participated in all triennial World Landslide Forum (WLF); and to the ICL thematic and regional networks where possible.

On behalf of the Government of Canada, GSC's activities under its core responsibility support Canada's efforts to address the UN 2030 Agenda and the achievement of several Sustainable Development Goals (SDG) including the Sendai Framework for Disaster Risk Reduction 2015-2030. NRCan's work under the Emergency Management Strategy contributes to SDG 11, sustainable cities and communities through ongoing research, and the implementation 
of tools that reduce risk and prevent harm caused by natural hazards including landslides. In 2019, the GSC signed the KLC 2020 and will strongly support its actions.1030

\section{Department of Civil and Environmental Engineering, University of Alberta}

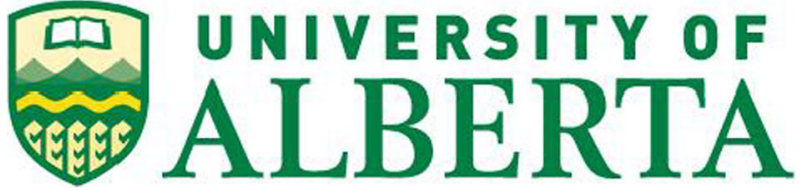

Date of signature: 18 September 2019

URL: www.ualbertageotech.ca

The University of Alberta (UAlberta) Geotechnical Centre is a rigorous and active research team of 9 faculty members and over 100 graduate students, postdoctoral fellows, research associates, and technicians. Our faculty members' expertise spans a range of geotechnical and geoenvironmental engineering subjects, including landslides and ground hazards, railway engineering, geomechanical reservoir engineering, and cold regions engineering, among others. UAlberta has a prolific and internationally esteemed history of research, development, and practice in landslides and ground hazards research, and our academics have a track record of high-level involvement (e.g., Distinguished University Professor Emeritus N.R. Morgenstern was an Expert Advisory Committee Member for the United Nations International Decade for Natural Disaster Reduction, and Associate Professor Michael Hendry is the Principal Investigator for our current World Centre of Excellence (WCoE) designation (2017-2020)). Details of the breadth, depth, and track record of our Centre can be found at www.ualbertageotech.ca.

Since 2017, UAlberta has been a full member of the International Consortium on Landslides (ICL) and was awarded the title of WCoE in landslide risk reduction for the period of 2017-2020. Our Centre's ongoing research and programs at UAlberta strongly align with the objectives of the 2030 Agenda for Sustainable Development, the Sendai Framework for Disaster Risk Reduction 2015-2030, and especially KCL 2020 Actions 1, 2, 3, 5, 6, 8, 9, and 10. Our research activities focus on evaluating the performance of monitoring technologies and remedial methods to mitigate natural hazards and the use of these technologies to find previously unidentified natural hazards. Through the Railway Ground Hazard Research Group (RGHRP), UAlberta made significant contributions to the understanding of natural hazards that impact railway operations and other types of linear infrastructure (e.g., quantifying the hazard posed by rock falls and developing correlations between the temporal distributions of rock falls to climatic conditions). Through the Ripley Landslide, a national collaborative multi-sector research site with Transport Canada, the Geological Survey of Canada, and Canadian National and Canadian Pacific Railways, UAlberta significantly contributes to the testing of multiple landslide monitoring technologies, ranging from space-based InSAR (provided by the Canadian Space Agency) and novel acoustic systems to traditional natural instruments. This comprehensive technology testing program allows comparisons of the accuracy of these systems and their suitability and usefulness. Our Centre conducted a comprehensive investigation of the site with boreholes, geophysics, and laboratory testing. This work represents a cumulative investment of over $\$ 1,000,000 \mathrm{CAD}$ in instrumentation, drilling, laboratory testing, and geophysics. The site is opened to other researchers who wish to try new monitoring technologies at this site; this has led to collaboration with the Chinese Academy of Sciences, the British Geological Survey, and the University of Loughborough in the UK.

\section{Institute of Cold Regions Science and Engineering, Northeast Forestry} University

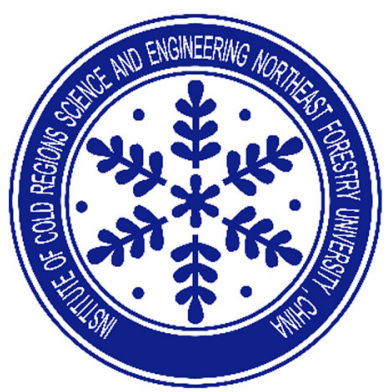

Date of signature: 18 September 2019

URL: http://en.nefu.edu.cn/

Institute of Cold Regions Science and Engineering of Northeast Forestry University (ICRSE-NEFU) is committed to the environmental geology and engineering geology of high-latitude permafrost region and deep seasonal frozen area under the background of climate change and attaches importance to the combination of basic research and applied research. With undergraduate, master, doctor, and postdoctoral professional training system and standards, combined with regional development needs, ICRSE-NEFU initiated "Geological environment risk research plan for permafrost degraded areas in Northeast China (GERRP)." In order to accumulate long-term field observation data, with the support of the Chinese government, "Field scientific observation and research station of the Ministry of Education - Geological environment system of permafrost area in Northeast China (FSSE-PFNEC)" was established. Its observation stations cover all kinds of permafrost areas in Northeast China. At the same time, in order to develop and transfer technologies related to environmental governance and transportation infrastructure construction in permafrost regions, "Provincial Collaborative Innovation Centre Environment and road construction \& maintenance in permafrost area of Northeast China (PCIC-PFER)" was established. Over the years, ICRSE-NEFU have continuously established cooperation with academic institutions and organizations at home and abroad, held various academic exchanges and regularly held "Academic Seminar on Engineering Geology and Environmental Geology in the Permafrost Along the Sino-Russian-Mongolian Economic Corridor," edited and published research cases of geoenvironmental disasters in permafrost regions in Northeast China, and shared the research results of GERRP. At present, the research results of GERRP are gradually enriched, and some of them have highly academic value and have been put into engineering practice.

ICRSE-NEFU has gradually shown its unique research charm since it became an ICL member in 2002. In 2012, ICRSE-NEFU established a landslide research network in cold regions (ICLCRLN) and held its first academic meeting in Harbin, China, in 
July 2014. The conference exchange results were published in Springer. ICRSE-NEFU is also one of the conveners of all previous World Landslide Forum (WLF) — the session of Landslide in Cold Region, as well as is the location of $\mathrm{WCoE}$ (landslide research in cold regions). It has several research projects approved by IPL Global Promotion Committee. At WLF3 held in Beijing in 2014, the research results were recognized and awarded by UNESCO. ICRSE-NEFU continuously contributes to the 2030 Agenda for Sustainable Development, as well as to the Sendai Framework for Disaster Risk Reduction 2015-2030. Therefore, in 2019, ICRSENEFU signed KLC 2020 and will strongly support its actions, especially KLC 2020 Actions 1, 2, 3, 5, 9, and 10.

\section{Faculty of Engineering, China University of Geosciences (Wuhan)}

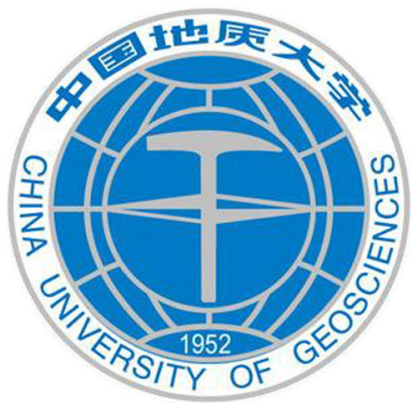

Date of signature: 18 September 2019

URL: http://en.cug.edu.cn/

China University of Geosciences (CUG), founded in 1952, is a national key university affiliated with the Ministry of Education. It is listed in the National "211 Project," the "985 Innovation Platform for Advantageous Disciplines" and the "Double First-class Plan." CUG, featuring geosciences, is a comprehensive university that also offers a variety of degree programs in science, engineering, literature, management, economics, law, education, and arts. The subjects of Geology and Geological Resources and Geological Engineering at CUG have both been top-ranked in China since its foundation. Its Earth Science, Engineering, Environmental Studies and Ecology, Materials Science, Chemistry, and Computer
Science have entered the top $1 \%$ of global ESI (Essential Science Indicators), with Earth Science in the top 1\%o of the list.

CUG, covering technical disciplines of geological engineering and civil engineering, as well as groundwater science and geodetic engineering, has been involved in landslide risk reduction activities in China for decades. The research groups of CUG have obtained remarkable achievements in the prevention and mitigation of landslide geohazards. For example, CUG has built an Experimental Site of geohazards inside a giant landslide in Badong County and has established the Model District of the National Comprehensive Geohazards Control in Three Gorges Reservoir Area, providing plenty of materials for research, teaching, and training of landslide geohazards all around the world.

CUG, as a full member of the International Consortium on Landslides (ICL), has been gradually intensifying its contributions to the ICL worldwide efforts for landslide risk reduction and control study. Badong International Geohazards Symposium (BIGS2017 and BIGS2019) series initiated by CUG, based on the Experimental Site and the Model District, have become a wellknown brand and offered a great opportunity for scholars around the world to communicate and cooperate in prevention and mitigation of landslide geohazards.

In 2019, CUG signed KLC 2020 in Paris and will strongly support its actions, especially KCL 2020 Actions 2, 3, 6, 9 and 10.

\section{References}

Sassa K (2019) The Kyoto Landslide Commitment 2020: first signatories. Landslides 16(11):2053-2057

Sassa K (2020) Launching Session of the Kyoto Landslide Commitment 2020. Landslides 17:1743-1744

Sassa K (2021) The Kyoto Landslide Commitment 2020. Launched, Preface, Landslides 18(1). https://doi.org/10.1007/s10346-020-01575-4

Publisher's note: Springer Nature remains neutral with regard to jurisdictional claims in published maps and institutional affiliations.

K. Konagai $(\varangle)$

International Consortium on Landslides,

Kyoto, Japan

Email: kaz3776k@gmail.com 